\title{
Anti-Reflection Mechanism of the Coalmass under the Liquid Carbon Dioxide Phase Change Gas Explosion and the Experimental Study
}

Yun Lei ( $\nabla$ xlding2015@yeah.net)

Shenyang Research Institute, China Coal Technology \& Engineering Group Corp

Research

Keywords: Low-permeability, Gas-rich, Carbon dioxide, Anti-reflection, Gas explosion

Posted Date: August 10th, 2021

DOI: https://doi.org/10.21203/rs.3.rs-779337/v1

License: (c) (1) This work is licensed under a Creative Commons Attribution 4.0 International License.

Read Full License 


\title{
ANTI-REFLECTION MECHANISM OF THE COALMASS
}

\author{
UNDER THE LIQUID CARBON DIOXIDE PHASE \\ CHANGE GAS EXPLOSION AND THE EXPERIMENTAL
}

\section{STUDY}

\author{
Yun Lei ${ }^{1,2}$ \\ 1. Shenyang Research Institute, China Coal Technology \& Engineering Group Corp, Fushun 113122, \\ China
}

2. State Key Laboratory of Coal Mine Safety Technology, Fushun 113122, China

\begin{abstract}
The problems of high efficient coal and gas simultaneous extraction of the low-permeability and high-gas coal seams in deep mines are major problems that restrict the sustainable development of China's coal industry. In order to solve the scientific permeability problem of the high gassy coal seams with low permeability under deep and complex geological conditions, a technology of liquid carbon dioxide phase change gas explosion for cracking and antireflection is proposed. The formation mechanism of the coalmass fracture circle resulting from liquid carbon dioxide phase change gas cracking coal is analyzed theoretically and a mathematical model within the range of fracture circle is established. Numerical simulation analysis shows that a blasting crushing zone with a radius of $1.0 \mathrm{~m}$ formed around the blasting hole. The radius of the secondary expansion zone caused by the explosion gas to promote coalmass formation is $2.0 \mathrm{~m}$, and the limit extension length of the explosion fracture is $2.3 \mathrm{~m}$. The gas phase change gas explosion is determined by the coal roadway driving face based on the gas content index and the analytical index of coal shavings to be able to reduce the pre-drainage time of coal roadway from 30 days to 15 days and 16 days. The comparison experiment also reaches a conclusion that the initial gas emission is increased by 3.7 times from the 100-meter borehole in the original coalmass after coalbed gas explosion anti-reflection. The results of the theoretical analysis are verified by underground experiments in the coal mine.
\end{abstract}

Key words: Low-permeability, Gas-rich, Carbon dioxide, Anti-reflection, Gas explosion 


\section{Introduction}

China is the largest coal consumer and producer in the world. The coal reserves of China account for $45.7 \%$ of the world's proven reserves. Coal production accounts for $38.2 \%$ of the world's total production. Both reserves and production rank first in the world. Coal occupies an important role in China's energy structure and accounts for about $70 \%$ of the total energy. Coal plays an important role in the development of China's national economy (Qiang Wang et al.,2017; Erzi Tang et al.,2017). As one of the world's leading coal producers, the death toll from coal mine accidents in China is more than three times higher than the total number of coal-producing countries in the world. Among them, gas accidents in coal mines are particularly serious, accounting for more than 35\% of China's coal mine accidents (Wentao Yin et al.,2017). With the depletion of coal resources in China's shallow reserves areas, the mining development of mines gradually enters the deep zone where the coal seam is buried. The gas content of the coal seam is directly proportional to the thickness of the overlying bedrock, and the mines gradually become high gas mine from the original low gas mine according to gas emission during the mine excavation process, while China's deep mines generally have poor technical difficulties caused by poor permeability of coal seams, so coal gas problems will long-term constraints on China's coal production safety (Kan Jin et al.,2016; Bevin Durant et al.,2016).

The problems of high efficient coal and gas simultaneous extraction of the low-permeability and high-gas coal seams in deep mines are major problems that restrict the sustainable development of China's coal industry(Bingxiang Huang et al.,2016; Yun Lei et al.,2017). In order to solve the scientific permeability problem of the high gassy coal seams with low permeability under deep and complex geological conditions, a technology of liquid carbon dioxide phase change gas explosion for cracking and antireflection is proposed. The basic principle of liquid carbon dioxide phase change blasting anti-reflection technology is to add liquid carbon dioxide of rated capacity into the cracker on the ground or in the downhole. After the filling is completed, a single cracker in series is placed in the blast hole, and the blasting of the crackers is started with the mining exploder from a long distance. The blast wave and blasting gas generated by the blasting directly act on the borehole coal wall to promote a large number of cracks in the coalmass and finally achieve the purpose of anti-reflection for the coal seam with low permeability(Haidong Chen et al.,2017; 
Yunxing Cao et al.,2017; XuelinYang et al.,2019). As a new technology applied to coal mines, the inspection experiments on the anti-reflection mechanism and anti-reflection effect of liquid carbon dioxide phase change gas explosion anti-reflection technology for coal seam need to be further studied.

\section{Analysis of formation mechanism of coalmass fracture circle in phase change blasting of liquid carbon dioxide}

According to the theory of elasticity, it can be known that the stress state at any point around a blast hole in a coal seam can be expressed as

$$
\left\{\begin{array}{l}
\sigma_{\text {rrgeo }}=-\frac{\sigma_{\text {yygeo }}}{2}\left[(1+K)\left(1-\frac{r_{b}^{2}}{r^{2}}\right)-(1-K)\left(1-\frac{4 r_{b}^{2}}{r^{2}}+\frac{3 r_{b}^{4}}{r^{4}}\right) \cos 2 \theta\right] \\
\sigma_{\theta \theta g e o}=-\frac{\sigma_{y y g e o}}{2}\left[(1+K)\left(1-\frac{r_{b}^{2}}{r^{2}}\right)+(1-K)\left(1-\frac{4 r_{b}^{2}}{r^{2}}+\frac{3 r_{b}^{4}}{r^{4}}\right) \cos 2 \theta\right] \\
\tau_{\text {regeo }}=-\frac{\sigma_{\text {yygeo }}}{2}\left[(1-K)\left(1+\frac{r_{b}^{2}}{r^{2}}-\frac{3 r_{b}^{4}}{r^{4}}\right) \sin 2 \theta\right]
\end{array}\right.
$$

In the formula, $\sigma_{\text {rrgeo }}, \sigma_{\theta}$ geo, $\sigma_{\text {r } \theta g e o}$ are the state of stress at any point of the coalmass in polar coordinates; $\sigma_{\text {yygeo }}$ is the vertical crustal stress component; $\mathrm{K}$ is the side pressure coefficient of horizontal crustal stress; $\theta$ is the angle between polar coordinates and horizontal direction.

There is a gap between the cracker and the blast hole, which is an uncoupled burst blast. The initial peak pressure of the blast hole can be expressed as follows

$$
p_{c}=\frac{1}{2(1+\gamma)} \rho_{0} D_{v}^{2} n
$$

In the formula, $\rho_{0}$ is liquid carbon dioxide density at room temperature, $\mathrm{kg} / \mathrm{cm}^{3}$; $D_{v}$ is cracker blasting gas detonation speed, $\mathrm{m} / \mathrm{s} ; \gamma$ is the expansion adiabatic index of carbon dioxide phase-change detonation products, usually $\gamma=3 ; n$ is the pressure increase coefficient of the detonation gas explosion, generally $n=10$. 
The mechanical model within the fracture circle range of the coalmass with borehole in the coal seam under gas explosion is shown in Fig.1. In the figure, R1 is the effective range of the fracture circle under gas explosion.

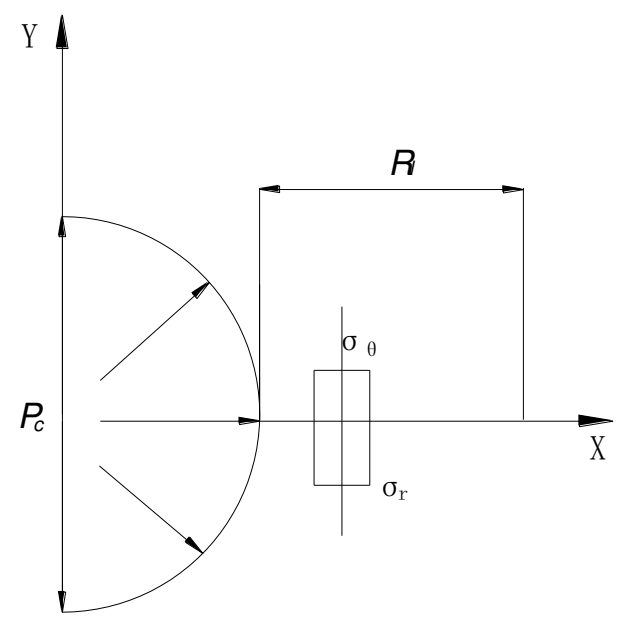

Fig.1 The mechanical model within the fracture circle range of the coalmass with borehole in the coal seam under gas explosion

The gas explosion pressure peak value of liquid carbon dioxide phase change has a big difference with explosives. It has been shown that liquid carbon dioxide phase change gas explosion is more difficult to form a large area of crushing circle. This paper focuses on the study of the scope of the fracture circle formed by liquid carbon dioxide phase-change gas explosion. When the gas explosion shock wave decays into a compressive stress wave, the coalmass generates compressive stress and compressive deformation in the radial direction of coalmass. Tensile stress and deformation will also be produced from the tangential direction. Due to the poor tensile strength of the coalmass, when the tangential stress of the coalmass exceeds its tensile strength, fracture will be generated in the radial direction.

There are studies showing that the gas shock wave attenuates very quickly in the coalmass and the peak pressure can be expressed as with the change rule of distance:

$$
P(r)=P_{c}(\bar{r})^{-\alpha_{s}}
$$




$$
\begin{gathered}
\bar{r}=r / r_{b} \\
\alpha_{s}=[2-\mu /(1-\mu)]
\end{gathered}
$$

In the formula, $\bar{r}$ is the specific distance; $\gamma$ is the distance from the explosion borehole; $\alpha_{s}$ is the attenuation coefficient of shock wave in the crush zone; $\mu$ is Poisson's ratio of coalmass.

When the explosion shock wave propagates to the boundary of compression zone, the shock wave decays to the form of stress wave. According to the law of conservation of momentum, the pressure peak Pm at the edge of the impact zone of the coalmass is expressed as

$$
P_{m}=\rho_{c} c_{p} V_{r}
$$

In the formula, $\rho_{\mathrm{c}}$ is the density of coalmass, $\mathrm{kg} / \mathrm{m}^{3} ; \mathrm{c}_{\mathrm{p}}$ is a decay of the wave velocity of elastic stress wave, $\mathrm{m} / \mathrm{s} ; \mathrm{V}_{\mathrm{r}}$ is the displacement velocity of coal rock mass at the edge of shock wave transmission, $\mathrm{m} / \mathrm{s}$;

Based on the Poisson effect, the peak value of the tangential tensile stress generated by the gas explosion stress wave in the fracture region can be expressed as

$$
\sigma_{\theta \theta \max }=P_{m}\left[\frac{\mu}{1-\mu}\left(\frac{r_{b}}{r}\right)^{\alpha}\right]
$$

Since the stress peak value of the gas explosion in the fracture zone is greater than the peak value of the shock wave in the crush zone, considering the influence from the high ground stress suffered by the coalmass around the explosion borehole on the gas explosion crack, the total tangential stress of any point of coalmass within the gas explosion fracture area can be expressed as

$$
\sigma_{\theta \theta 1}=\sigma_{\theta \theta \max }+\sigma_{\theta \theta g e o}=P_{m}\left[\frac{\mu}{1-\mu}\left(\frac{r_{b}}{r}\right)^{\alpha}\right]+\sigma_{\theta \theta g e o}
$$

Replace $\sigma_{\theta \theta 1}$ in formula (8)with the dynamic strength of extension of coalmass $\sigma_{d t}$, that is, to obtain the extension range causing the crack on radial direction after the gas explosion

$$
r_{c}=r_{b}\left(\frac{\mu P_{m}}{(1-\mu)\left(\sigma_{d t}-\sigma_{\theta \theta g e o}\right)}\right)^{\frac{1}{\alpha}}
$$


Therefore, the effective range of the coalmass fracture circle caused by liquid carbon dioxide phase change gas explosion is

$$
R_{l}=r_{c}-r_{b}=r_{b}\left[\left(\frac{\mu P_{m}}{(1-\mu)\left(\sigma_{d t}-\sigma_{\theta \theta g e o}\right)}\right)^{\frac{1}{\alpha_{s}}}-1\right]
$$

From the theoretical analysis and deduction above, it can be seen that the effective range of the fracture circle formed around the blast hole under the action of phase change gas explosion is not only related to the peak pressure of the carbon dioxide cracker explosion, but also related to the stress resistance of the coal seam and the physical properties of the coal.

\section{Study on numerical simulation of gas-explosion-induced cracking in liquid carbon dioxide}

The numerical simulation was targeted on the coal mass extracted from No.15203 working face in Area 2 of No.15 Coal Seam, Mapu Mine, northeastern of Qinshui Coal Mine, Shanxi Province. The geometric model of granular discrete element PFC2D established is illustrated in Fig.1. In the $16 \mathrm{~m} \times 16 \mathrm{~m}$ model, the boundary of the model was set as "wall" which played the role as the boundary of the model and particle escape protector after blasting at the central point. The peak pressure for $\mathrm{CO}_{2}$ phase-transition blasting was taken as $200 \mathrm{MPa}$ in the numerical simulation.

In the simulation, the central point served as the blasting borehole, its diameter was set as $0.113 \mathrm{~m}$, particle radius as $0.006-0.009 \mathrm{~m}$, porosity of particle aggregate 0.1 , and density of particle aggregate $1,521 \mathrm{~g} / \mathrm{m}^{3}$. 


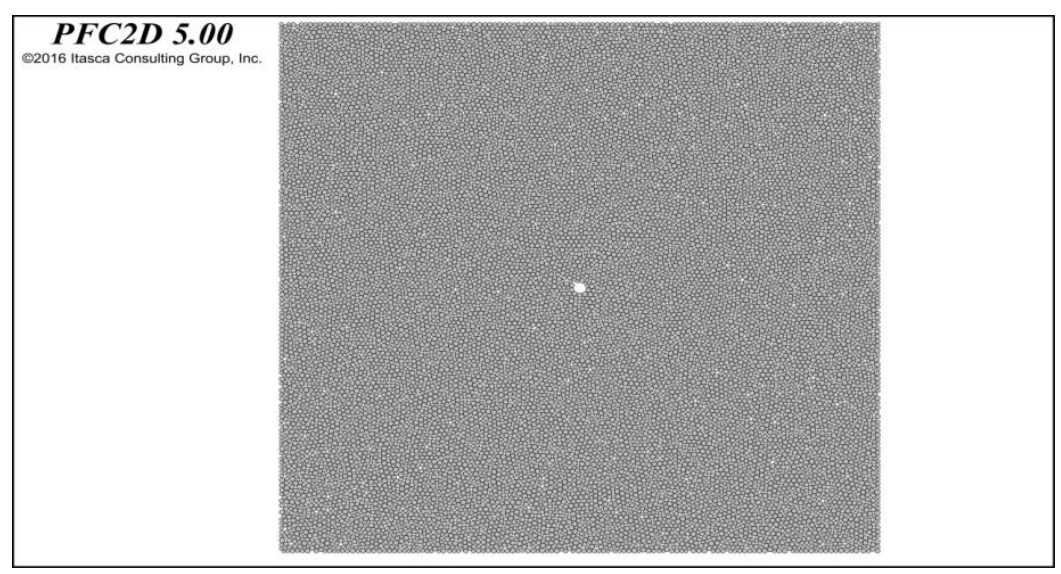

Fig. 2 Geometric model of PFC2D

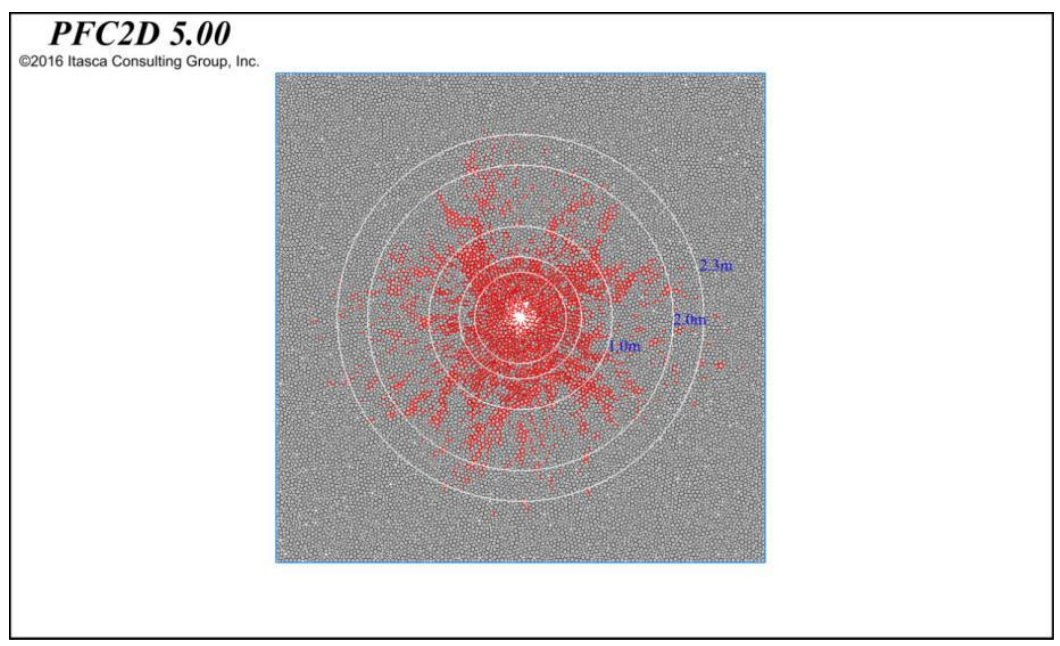

Fig. 3 State of particles and fracture propagation after blasting

The numerical simulation results in Fig. 3 reveal that the blasting gives rise to a $1 \mathrm{~m}$ crushed zone around the borehole, which means the destructed zone of the gas-rich coal seam resulting from the blasting is $1 \mathrm{~m}$ in radius; they also indicate that the maximum range of the secondary expanded zone of cracks from the blasting is $2 \mathrm{~m}$, which means the damaged zone of the gas-rich coal seam is $1 \mathrm{~m}-2 \mathrm{~m}$ in radius, and the ultimate extension length of the explosion fracture is $2.3 \mathrm{~m}$. 


\section{Experimental study on liquid carbon dioxide phase change gas-explosion-induced cracking anti-reflection in coal roadway heading face}

\subsection{Experimental work surface overview}

Experimental study on liquid carbon dioxide phase change gas-explosion-induced cracking anti-reflection in coal roadway heading face is implemented in the 15th coal seam 15203 wind crossheading coal roadway driving face. The distance of the working surface from the No.9 coal seam is $47.24-71.63 \mathrm{~m}$, and the average is $56.39 \mathrm{~m}$. The thickness of coal seam is $4.8-6.2 \mathrm{~m}$, and the average thickness is $5.5 \mathrm{~m}$, containing 0-3 layers of dirt band. The structure is relatively simple, and the recoverability index $\mathrm{Km}=1$ with variation coefficient of $18 \%$. It is a stable and recoverable coal seam in the whole region. Coal quality is ultra-low ash - medium-high ash, medium sulfur- high sulfur, low-to-moderate calorific value - extra-high lean coal (SM), meager lean coal (PS), and meagre coal (PM). The overall layout of the working face is a monoclinic structure, which leads to NNE, tends to NWW, and is expected to have a gradient of $0-4^{\circ}$, thus it is relatively flat. Driving face adopts press-in type ventilation method and the method of gas drainage before excavation to control gas, and the pre-extraction time is 1 month. The original coal gas basic parameters measured before the gas-explosion-induced cracking anti-reflection experiment at the working face is implemented are shown in Table 1.

Table 1 . The original gas basic parameter table of the experimental coal roadway driving face

\begin{tabular}{|c|c|c|c|c|c|c|}
\hline $\begin{array}{l}\text { Name } \\
\text { Of } \\
\text { Gas } \\
\text { parameters }\end{array}$ & $\begin{array}{l}\text { Gas } \\
\text { content } \\
/ \mathrm{m}^{3} \cdot \mathrm{t}^{-1}\end{array}$ & $\begin{array}{l}\text { gas gushing } \\
\text { amount per } 100 \\
\text { meters borehole } \\
/ \mathrm{m}^{3} \cdot(\text { min.hm })^{-1}\end{array}$ & $\begin{array}{l}\text { Natural gas } \\
\text { gushing } \\
\text { attenuation } \\
\text { coefficient } \\
/ \mathrm{d}^{-1}\end{array}$ & $\begin{array}{l}\text { Gas } \\
\text { pressure } \\
/ \mathrm{MPa}\end{array}$ & $\begin{array}{l}\text { Seam } \\
\text { permeability } \\
\text { coefficient } \\
/ \mathrm{m}^{2} \cdot \mathrm{MPa}^{-2} \cdot \mathrm{d}^{-1}\end{array}$ & $\begin{array}{l}\text { Pre-extraction } \\
\text { time /mon }\end{array}$ \\
\hline \multicolumn{7}{|l|}{ Actual } \\
\hline $\begin{array}{l}\text { Value } \\
\text { measured }\end{array}$ & 7.54 & 0.0865 & 0.035 & 0.57 & 1.32 & 1 \\
\hline
\end{tabular}




\subsection{Design of the liquid carbon dioxide phase change gas-explosion-induced cracking anti-reflection on coal roadway heading face}

In the 15203 coal roadway working face, the liquid carbon dioxide phase change gas-blast-induced cracking and anti-reflection experiment is carried out to improve the permeability of the coalmass ahead of the excavation and shorten the pre-extraction time of excavation face, thereby realizing coal road speedy drivage technology guided by liquid carbon dioxide phase change blasting. The layout schematic diagram of the borehole of gas blast experiment on the coal roadway driving face is shown in Figure 4 and Figure 5.

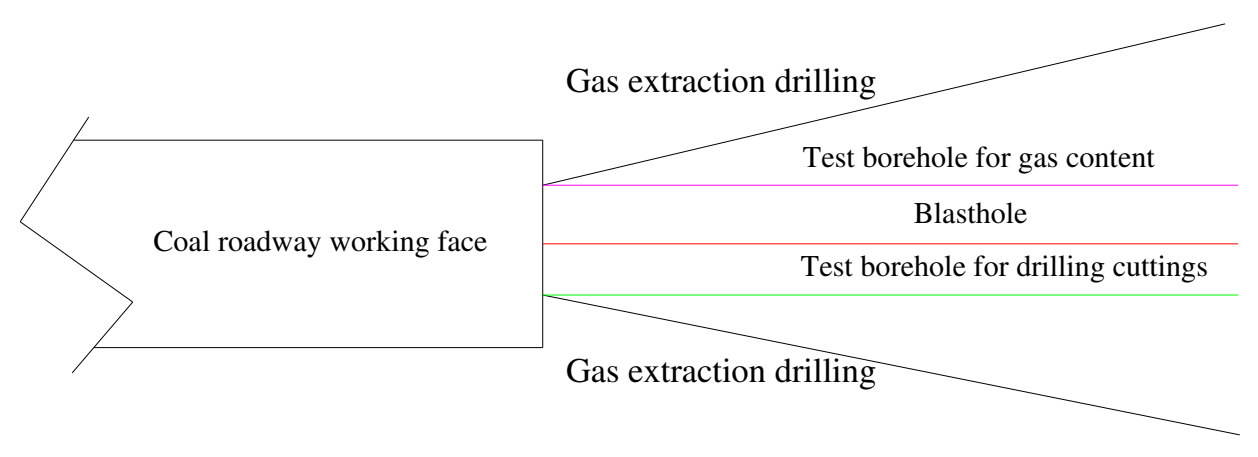

Fig. 4 Borehole layout plane schematic of gas-blast anti-reflection experiment on the coal mine roadway working face 


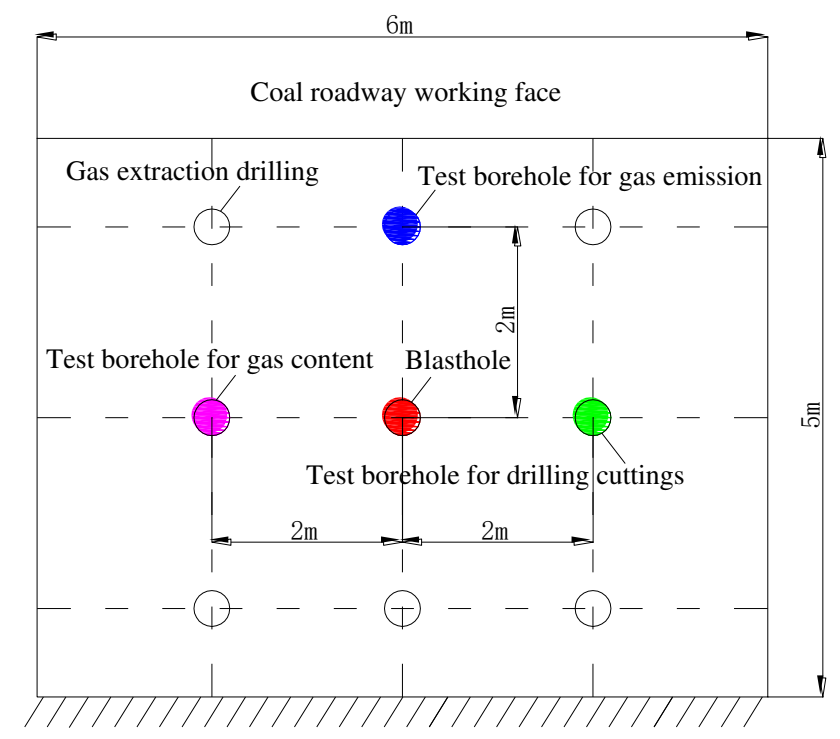

Fig. 5 Borehole layout plane schematic of gas-blast anti-reflection experiment on the coal mine roadway working face

Table 2. Test borehole construction parameter table

\begin{tabular}{lllll}
\hline Borehole name & Hole height/m & $\begin{array}{l}\text { Bore } \\
\text { diameter } / \mathrm{mm}\end{array}$ & $\begin{array}{l}\text { Borehole } \\
\text { depth/m }\end{array}$ & azimuth angle $/^{\circ}$ \\
\hline Blasthole & 3.5 & 94 & 50 & Vertical coal wall \\
Test borehole for gas content & 3.5 & 94 & 50 & Vertical coal wall \\
Test borehole for gas emission & 5.5 & 94 & 50 & Vertical coal wall \\
Test borehole for drilling cuttings & 3.5 & 94 & 50 & Vertical coal wall \\
\hline
\end{tabular}

\subsection{Analysis of experimental results of phase change gas-blast-induced cracking and anti-reflection in coal roadway heading face}

For this liquid-carbon dioxide phase change gas-blast-induced cracking anti-reflection experiment in the coal seam driving face, the blasting depth is $50 \mathrm{~m}$. Because the new-excavated working face does not have the problem to preclude the 
gas zone, the sealing depth is $7 \mathrm{~m}$. After the gas blast anti-reflection test, connect the extraction drill holes for pre-drainage. After the gas explosion, the corresponding parameters of the test boreholes are tested daily to get the gas content Wh and the coal drilling cuttings analysis index $\triangle \mathrm{h}_{2}$. The SYQY-73 fixed-point rapid sampling equipment is used to measure the gas content, and MD-2 coal-drill cutting gas analysis instrument is used to measure the analytical index of the coal cuttings, as shown in Figure 6. The picture of the driving face before and after blasting in coal mine heading is shown in Figure 7.

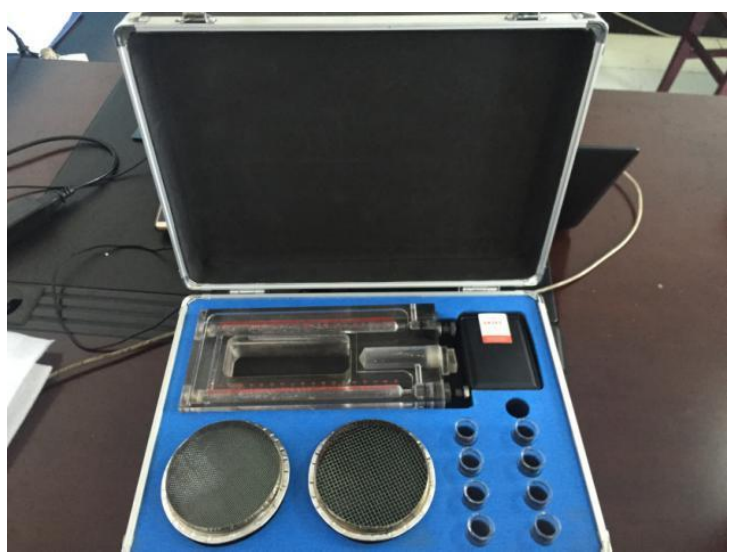

Fig.6 MD-2 coal drilling cuttings desorber

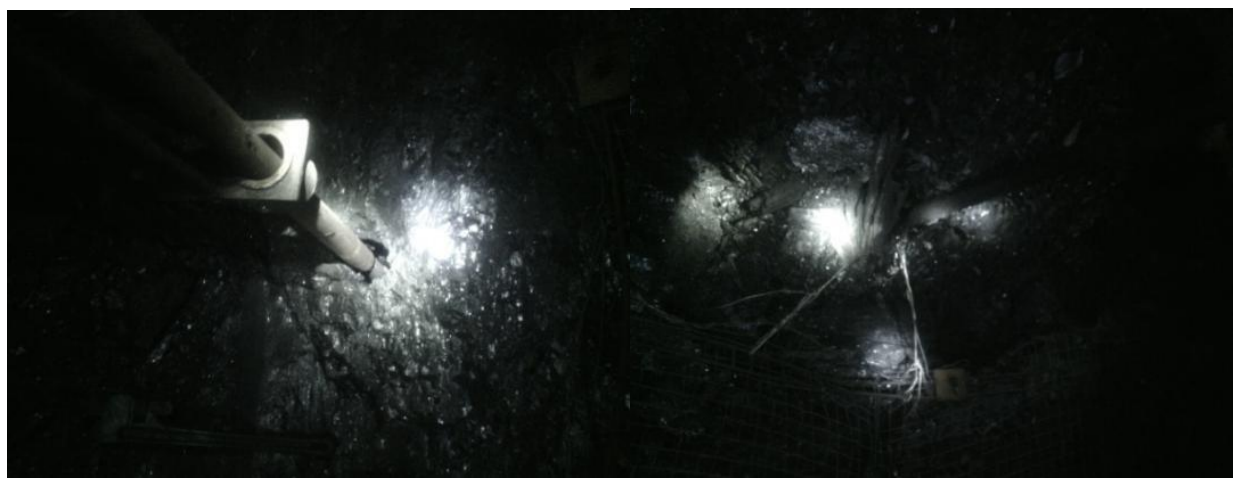

(a) Before explosion

(b) After explosion

Fig.7 On-site picture of coal road heading driving face before and after blasting 


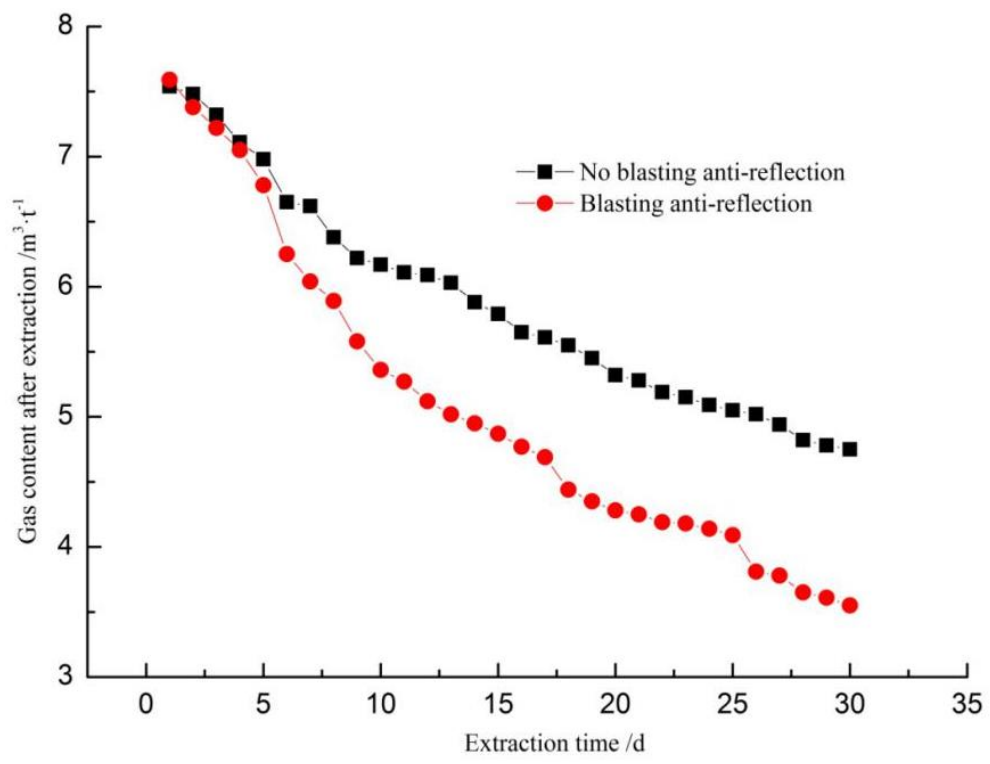

Fig. 8 Variation diagram of gas content before and after the blasting of coal road heading driving face

It can be seen from Fig. 8 that shows gas content changing scheme with the predrainage time for whether the coal road heading driving face adopts the gas-explosion-induced cracking anti-reflection that the influence of the negative pressure pre-drainage will gradually reduce the gas in the coalmass in the direction of coal roadway excavation. When the gas-explosion-induced cracking anti-reflection is not used, it will cost 1 month for pre-drainage to reduce the gas content of the raw coal to less than $5 \mathrm{~m} 3 / \mathrm{t}$; when the gas-explosion-induced cracking anti-reflection is used, the reduction rate of gas content of the raw coal is significantly accelerated under the effect of pre-drainage. It can be seen that the gas content is reduced to less than $5 \mathrm{~m} 3 / \mathrm{t}$ with about 15 days pre-drainage. It can be determined that gas-explosion-induced cracking anti-reflection can increase the gas permeability of the coal and improve the pre-drainage efficiency of coal seam, thereby achieving the goal of rapid excavation in high gassy coal roadway with low permeability. 


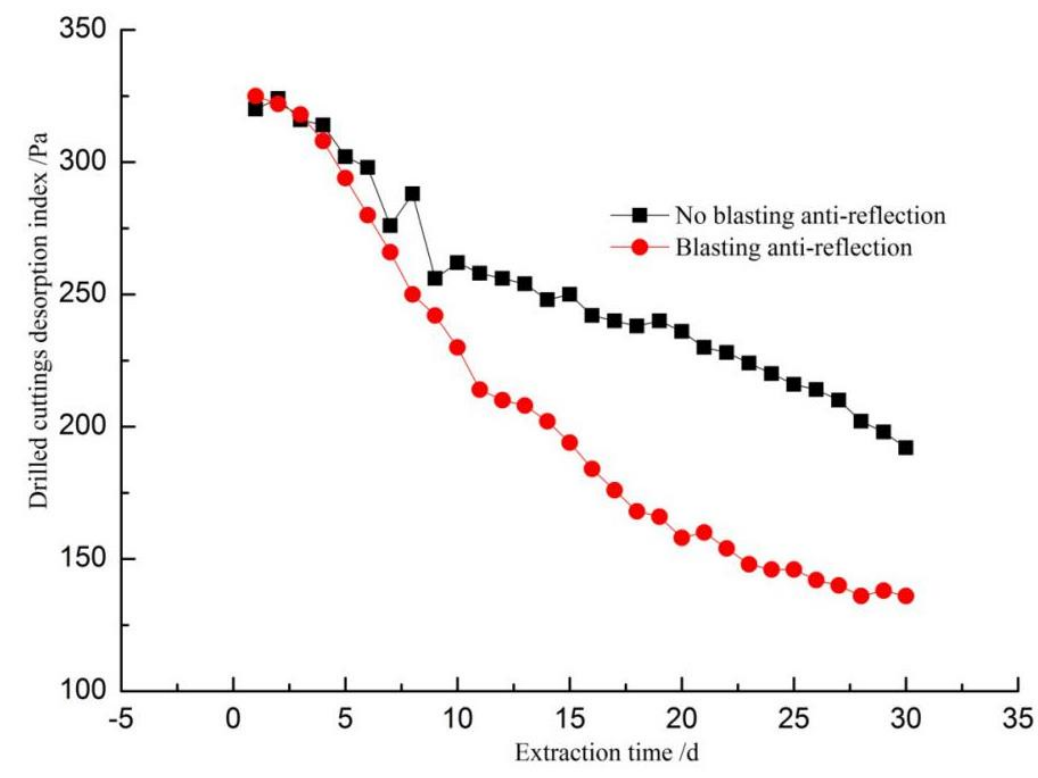

Fig.9 Variation diagram of coal drilling cuttings analysis index before and after the blasting of coal road heading driving face with time

The analysis index $\triangle \mathrm{h}_{2}$ of coal drilling cuttings is an important index for judging the possibility of abnormal gas gushing ahead of the driving face. The detection index is widely used in high gas and outburst mining face. The residual gas content (gas pressure) of the coal drilling cuttings collected at the fixed point is released into the confined space, and the volume of the confined space is used to represent the volume of gas resolved. It can be seen from Fig. 9 that gas-explosion-induced cracking anti-reflection have a greater influence on the analysis index of coal drilling cuttings, and after the gas explosion, its decreasing speed is faster after gas explosion with pre-drainage time, and it decreases to a safety index less than $200 \mathrm{~Pa}$ in about 16 days. 


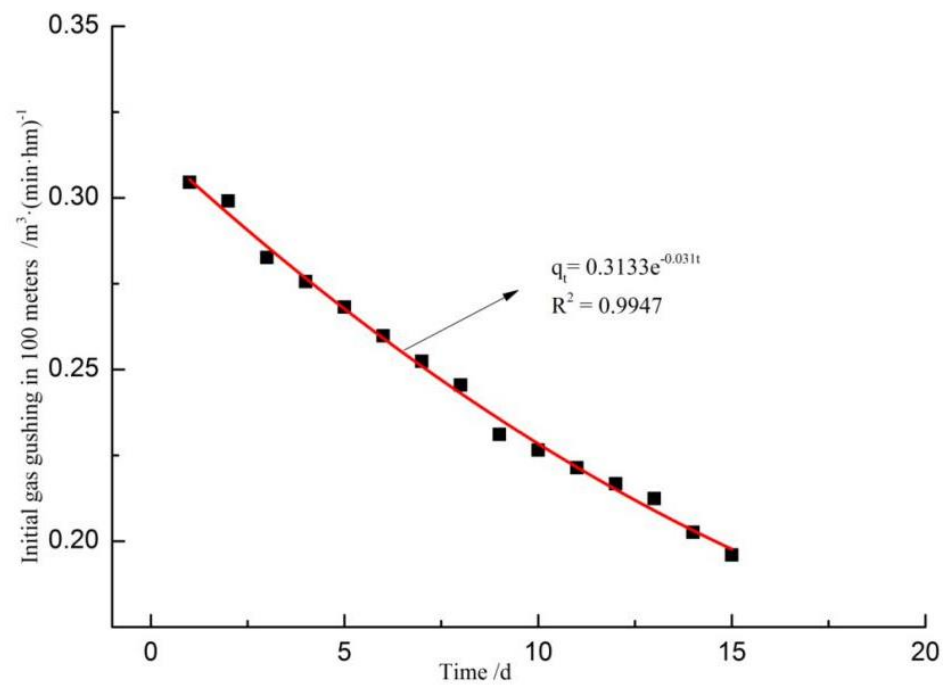

Fig.10 Attenuation curve of gas gushing from the gas-explosion controlling borehole in the coal roadway diving face

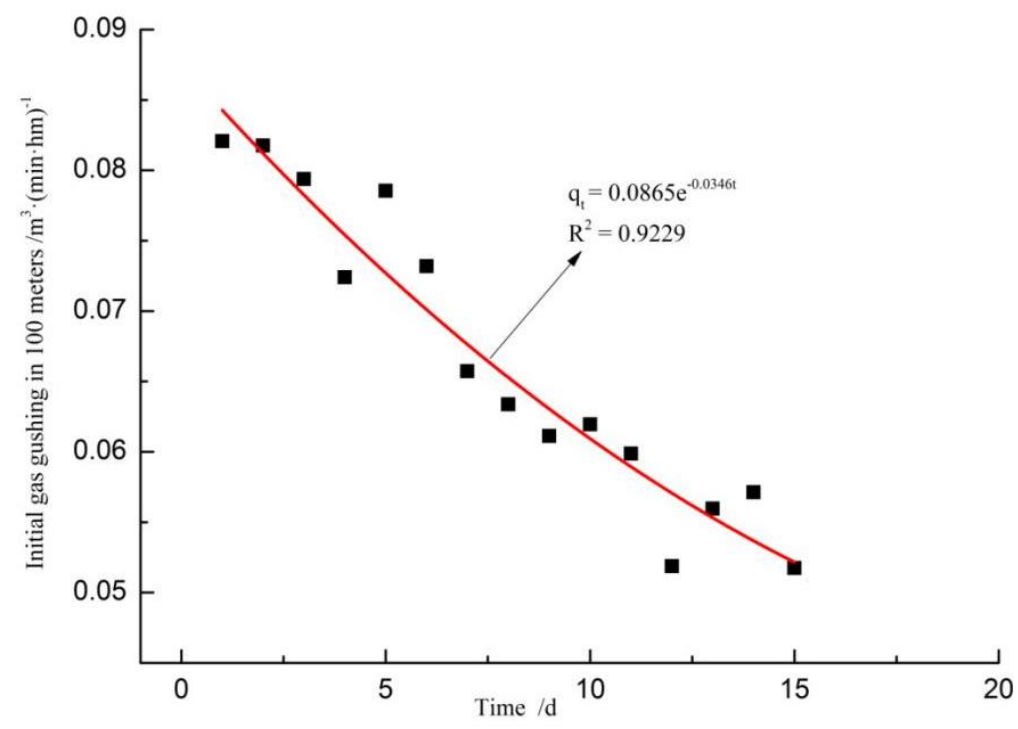

Fig.11 Attenuation curve of gas gushing from the original coalmass borehole in the coal roadway diving face

It can be seen from attenuation curve of gas gushing from the coal seam borehole in the coal roadway diving face in Figure 10 and Figure 11 that the initial gas gushing 
amount after coal seam borehole gas-explosion anti-reflection and $100 \mathrm{~m}$ test borehole drilled in the original coalmass are $0.3133 \mathrm{~m} / \mathrm{min} \cdot \mathrm{hm}$ and $0.085 \mathrm{~m} / 3 \mathrm{~min} \cdot \mathrm{hm}$ respectively, and the natural gas gushing attenuation coefficients are $0.031 / \mathrm{d}$ and 0.035/d respectively. From the measured results, it can be concluded that the initial gas gushing volume of coal seam borehole gas-explosion-induced cracking anti-reflection is 3.7 times than the gas gushing volume of original coalmass 100 meters borehole without anti-reflection measure. The anti-reflection effect of gas-explosion phase change cracking is obvious. The attenuation coefficient of natural gas gushing is very small, which is determined by the desorption speed of the coal itself.

\section{Conclusion}

The formation mechanism of the coalmass fracture circle in liquid carbon dioxide gas phase change cracking is discussed in depth. The mathematical model of the fracture circle range is deduced theoretically. It's confirmed that the effective range of the fracture circle is related to the explosion venting peak pressure of cracker, the coal seam stress, and the coal physical parameters. Numerical simulation analysis shows that the phase change gas explosion of liquid carbon dioxide causes a blasting crush zone with a radius of $1.0 \mathrm{~m}$ around the blasthole. The radius of the secondary expansion zone of the coalmass caused by the explosion gas is $2.0 \mathrm{~m}$, and the ultimate extension length of the explosion fracture is $2.3 \mathrm{~m}$. The experimental study on the driving face of the coal roadway shows that: after the liquid carbon dioxide phase change gas-explosion-induced cracking antireflection is adopted, the decreasing speed of the gas content of the raw coal under the negative pressure drainage is significantly accelerated. When the gas content of $5 \mathrm{~m} 3 / \mathrm{t}$ is used as the effective critical line to judge the pre-drainage, the gas-explosion anti-reflection reduces the pre-drainage time to 15 days from the original 30 days. When coal drill cuttings analysis index $200 \mathrm{~Pa}$ is used as a safety index to allow excavation, the gas-explosion antireflection reduces the pre-drainage time to 16 days from the original 30 days. The contrast test of coal seam borehole gas-explosion-induced cracking anti-reflection reaches a conclusion that the initial gas gushing volume of the $100 \mathrm{~m}$ coal seam borehole after gas-explosion 
anti-reflection is 3.7 times than that of the original coal, and the effect of gas-explosion-induced cracking anti-reflection is obvious.

\section{Acknowledgments}

This work was financially supported by the National Science and Technology Major Project (Grant No. 2016ZX05067004-003).

\section{Conflict of Interest}

The authors declare that they have no conflict of interest.

\section{Reference}

Qiang Wang, Rongrong Li. 2017, Decline in China's coal consumption: An evidence of peak coal or a temporary blip. Energy Policy, 108(9): 696-701.

Erzi Tang, Chong Peng, 2017. A macro- and microeconomic analysis of coal production in China. Resources Policy, 51(4): 234-242.

Wentao Yin, et al, 2017. 2017. Fatal gas explosion accidents on Chinese coal mines and the characteristics of unsafe behaviors. Safety Science, 92(2): 173-179.

Kan Jin, et al, 2016. Evaluation of the remote lower protective seam mining for coal mine gas control: A typical case study from the Zhuxianzhuang Coal Mine, Huaibei Coalfield, China. Journal of Natural Gas Science and Engineering, 33(7):44-55.

Bevin Durant, et al, 2016. Assessing dermal exposure risk to workers from flowback water during shale gas hydraulic fracturing activity. Journal of Natural Gas Science and Engineering, 34(8):969-978.

Bingxiang Huang, et al, 2016. Phenomenon of methane driven caused by hydraulic fracturing in methane-bearing coal seams. International Journal of Mining Science and Technology, 2016, 26(5):919-927.

Yun Lei, et al, 2017. Contrast test of different permeability improvement technologies for gas-rich low-permeability coal seams. Journal of Natural Gas Science and Engineering, 33(7):1282-1290.

Haidong Chen, et al, 2017. Increasing permeability of coal seams using the phase energy of liquid carbon dioxide. Journal of $\mathrm{CO}_{2}$ Utilization, 19(5):112-119.

Yunxing Cao, et al, 2017, $\mathrm{CO}_{2}$ gas fracturing: A novel reservoir stimulation technology in low permeability gassy coal seams[J]. Fuel, 203(9):197-207.

XuelinYang, et al, 2019. Environmentally friendly techniques for high gas content thick coal seam stimulation-multi-discharge $\mathrm{CO}_{2}$ fracturing system [J]. Journal of Natural Gas Science and Engineering, 61(1): 71-82. 